\title{
De arrochelados a vecinos: reformismo borbónico e integración política en las gobernaciones de Santa Marta y Cartagena, Nuevo Reino de Granada, 1740-1810
}

Por

\author{
Hugues R. Sánchez Mejía \\ Universidad del Valle, Colombia
}

Un mestizaje particular se generó en los siglos XVI y XVII en las gobernaciones de Santa Marta y Cartagena en el Nuevo Reino de Granada. La llegada del reformismo borbónico en cabeza del virrey don Sebastián Eslava a la ciudad de Cartagena en el año de 1740 tuvo un impacto importante sobre esa heteróclita población que para las autoridades "vivía sin Dios y sin ley». Si bien la coerción no estuvo ausente de las políticas de poblamiento que se realizaron para controlar gente que vivía en "rochelas» y/o arrochelada, esta no fue la fuerza principal que avalaba el éxito de la movilización de grupos de personas a lugares específicos llamados sitios de libres. Consideramos que una maniobra política determinada, la inserción a la vecindad y el vasallaje de descendientes libres de esclavos e indígenas, operada por el mencionado virrey están a la zaga de este proceso. Igual se muestra como, luego de ser incluidos en la vecindad y ser considerados vasallos del Rey, ahora los libres buscan mayor movilidad política.

Palabras Clave: Nuevo Reino de Granada; reformismo borbónico; zambaje; «rochelas»; «libres de todos los colores».

\section{INTRODUCCIÓN}

Un aspecto bastante estudiado del reformismo borbónico, aplicado en las gobernaciones de Santa Marta y Cartagena ${ }^{1}$ en el Nuevo Reino de Granada en

${ }^{1}$ Las gobernaciones de Santa Marta y Cartagena, fundadas en 1525 y 1537 respectivamente, comprendían el territorio de la llanura norte de lo que hoy es Colombia. La capital 
la segunda mitad del siglo XVIII, se relaciona con el tema del poblamiento, específicamente con las políticas de traslado, fundación de sitios y pueblos habitados por indígenas, descendientes de esclavos y sus mezclas raciales ${ }^{2}$. Varios trabajos revelaron la forma como funcionarios de la corona española, siguiendo órdenes impartidas por el virrey don Sebastián de Eslava, trazaron un plan que buscaba sacar de la «barbarie» política a una heteróclita población que se situaba en zonas rurales apartadas o a la veda de caminos, caños, ríos y ciénagas ${ }^{3}$. Fue así como se buscó dotar de policía y religión a pueblos que hasta ese momento vivían «sin ley ni orden» ${ }^{4}$. Esta faceta reformista tuvo etapas punitivas que centralizaron la mirada de la mayoría de historiadores ${ }^{5}$ y los llevó a una visión histórica bastante particular. Se sostenía que las campañas de poblamiento revelaban la aparición de un Estado Moderno con una capacidad de coacción muy efectiva ${ }^{6}$. Fue así como la perspectiva de un Estado omnipresente, «a la Foucault» ${ }^{7}$, que dominaba en todas partes hizo perder de vista varias particularidades e innovaciones políticas que se cristalizaron en ese periodo de tiempo ${ }^{8}$.

En una vía aparentemente opuesta sostenemos que si bien la coerción no estuvo ausente en las políticas de poblamiento que se realizaron en las mencionadas gobernaciones, esta no fue el nervio central, ni mucho menos el eje trascendental que garantizaba el éxito de la movilización de población a sitios predeterminados. Consideramos que -más bien- una operación política específica, la inserción a la vecindad y el vasallaje de descendientes libres de esclavos, indios y blancos pobres -hasta ese momento excluidos de ella- y llamados en el siglo XVIII «libres de todos los colores», está a la zaga de las campañas de poblamiento y de una serie de reformas que se aplicaron a partir de la llegada del virrey Sebastián de Eslava a la ciudad de Cartagena. El reformismo se mostró aquí inclusivo, cuestión que a nuestro parecer -siguiendo

de Santa Marta era la ciudad del mismo nombre y en su interior se ubicaban las ciudades de Valledupar, Tamalameque y Ocaña y la villa de Tenerife. En tanto Cartagena, la llave de las Indias, tenía en su jurisdicción las villas de Mompox, San Benito Abad, Ayapel y Tolú, y la ciudad de Simití.

2 Fals, 1979. Conde, 1999. Herrera, 2002a. Sánchez Mejía, 2004: 45-59.

${ }^{3}$ Estas campañas de poblamiento, viajes y exploraciones lideradas por funcionarios reales, obispos y curas durante el siglo XVIII no fueron únicas del Caribe colombiano, ver entre otros a Suárez y Tornay, 2003: 521-555. Rojas, 2010: 130-163.

4 Sánchez Mejía, 2008: 127-157.

5 De Mier, 1987. Mora de Tovar, 1993: 40-62. Moreno de Ángel, 1993.

${ }^{6}$ Herrera, 2002a: 24-34.

${ }^{7}$ La expresión es tomada de Tamar Herzog.

8 Pietschmann Horst, 1993: 52-83. 
a Paul Monod-, muestra la cara benévola de la instalación del llamado Estado Ilustrado en un área específica de la América Hispana ${ }^{9}$.

Así, expondremos cómo y desde qué momento, los llamados «libres de todos los colores» accedieron a la vecindad, aclarando que sí en algún momento estos estuvieron por fuera de ella, es decir no abrazaban la religión católica y no tenían deberes de vasallaje y mucho menos derechos, significaba que escapaban del régimen de restricción que tenía el sistema jurídico castellano para los que si vivían avecindados. Es decir, para usar el lenguaje de la época, eran libres de «cargas» y «tributos» para con una localidad. Con esto se confirma que antes de las reformas borbónicas se era libre cuando se estaba por fuera del Estado y no al revés como en el Estado Ilustrado, que garantizaba la libertad en cuanto esta se reglara por la ley y dentro de la vecindad y el vasallaje. De hecho la práctica del destierro por parte de los cabildos locales de sujetos declarados indeseables por la comunidad muestra una diferencia respecto de las disposiciones de los borbones, que en contravía del destierro decretan la prisión de los delincuentes.

Para demostrar lo anterior dividimos el presente artículo en dos partes. En el primer segmento buscamos develar el surgimiento de los lugares habitados por los llamados «libres de todos los colores», nombrados sitios de libres y/o «rochelas», en el tiempo y en el territorio que administrativamente se conoció como las gobernaciones de Santa Marta y Cartagena, señalando las particularidades de ese proceso. Observamos que un tipo de mezcla racial que se operó en las zonas rurales de las ciudades de Santa Marta, Cartagena y en la villa de Mompox, con el paso del tiempo generó un agrupamiento de personas en lugares que no encajaban en las normativas que el derecho castellano tenía para las fundaciones hechas en América. La mezcla racial entre negros e indios fue muy particular en las áreas rurales de las aludidas gobernaciones, lo que en un contexto específico permitió que se forjaran autonomías donde los descendientes ahora mixturados de esclavos e indígenas cimentaban variadas formas culturales.

Sostenemos que los sitios se ubicaban cerca de los centros urbanos hispanos y fueron incluidos a la vecindad desde comienzos del siglo XVIII, en tanto las «rochelas», por sus orígenes y organización política se acomodaron en montes y breñas y fuera de la jurisdicción de las formas jurídicas del derecho castellano. Para verificar el proceso de integración reformista intentaremos resolver ciertas cuestiones; primero, esclarecer las particularidades sociales y políticas de las personas que fueron incluidas como vecinos y, en segunda

\footnotetext{
9 Monod, 1996: 11-30; 2001: 58-110.
} 
instancia, clarificar qué individuos y por qué estos fueron llamados libres de condición política y de todos los colores en términos de mestizaje.

En la segunda parte del artículo revelaremos las características específicas de la integración borbónica en lo que respecta a los llamados derechos y deberes que adquieren los «libres de todos los colores», desde el acceso a tierras comunales a la calidad de milicianos. En este sentido, el hecho que en las aludidas gobernaciones existiera un nutrido grupo de personas que se encontraba por fuera de la vecindad y la necesidad de garantizar que milicianos y alimentos llegaran rápidamente a la ciudad de Cartagena, luego del ataque ingles a la ciudad de Cartagena en el año de 1741, fue el pretexto para que Eslava dotara de derechos y deberes a grupos de personas que no los poseían y, colocara a prueba el experimento ilustrado de un Estado bastante particular sin, eventualmente, chocar con los poderes de las administraciones locales.

Si bien la escasez de fuentes debilita la posibilidad de registrar las exigencias de derechos por parte de los «libres de todos los colores» en el contexto de la segunda mitad del siglo XVIII, algunos documentos que reposan en el Archivo General de la Nación de Colombia y el Archivo General de Indias muestran ya los efectos del reformismo en cuanto a las demandas de ascenso colectivo e individual por parte de la población incluida. Igual, los informes que se generaron por parte del maestre de campo José Fernando de Mier y Guerra en su campaña de poblamiento permiten intuir y develar la forma como fueron reglados a la vida en vecindad.

De Cómo El MESTIZAJE HIZO HOMBRES LIBRES

Empecemos entonces por el tema del mestizaje en las gobernaciones de Santa Marta y Cartagena y su interpretación según el derecho castellano. Los españoles se mezclaron con las mujeres indias y procrearon al conocido mestizo. Igual hicieron con esclavas o negras libres y concibieron el mulato. De esto último dio cuenta el jesuita José Gumilla a su paso por Cartagena en la segunda mitad del siglo XVIII, cuando observó que los «hombres blancos» tenían «inclinación y amor al color negro: y hoy en día, en Cartagena de Indias, en Mompox y en otras partes se hallan españoles honrados, casados (por su elección libre) con negras, muy contentos y concordes con sus mujeres.... ${ }^{10}$. Pero en las mencionadas gobernaciones también primó un tipo de mezcla racial bien particular resultado de tempranas uniones sexuales entre indíge-

10 Gumilla, 1781: 80 . 
nas y negros esclavos y la consecuente aparición de los llamados zambos ${ }^{11}$ o zambaigos, nombre con el que se conoció al hijo de indígena con negro en la América español ${ }^{12}$. Todas las anteriores mezclas estaban prohibidas por las leyes de Indias y eran consideradas ilegítimas por cuanto la mayoría no estaban sancionadas por el sacramento del matrimonio y el bautismo, lo cual los despojaba de los derechos ciudadanos como señala Solórzano: «el qual defecto de los natales les hace infames, por lo menos infame facti» ${ }^{13}$.

En cuanto a las particularidades de este tipo de mestizaje observamos que, de manera regular, se dieron casos en donde la relación sexual entre esclavos y las mujeres indias fue consentida. Al respecto un cronista afirmaba como en Perú «muchas indias dejan a sus maridos indios o aborrecen y desamparan los hijos que de ellos paren, viéndolos sujetos a tributos y servicios personales» y «desean, aman y regalan más los que fuera de matrimonio tienen de españoles, y aun de negros $\gg{ }^{14}$. En este sentido, las mujeres indígenas consideraban que por esa vía sus hijos escapaban del tributo y, dependiendo del contexto, ellas también podían hacerlo. Exonerarse del pago de tributos, mantener su sustento y garantizar su supervivencia son claves a la hora de entender la relación entre esclavos y mujeres indias ${ }^{15}$. En esto consideramos que el factor género tuvo incidencia en dicha ubicación social y política, como muestra Ares para Lima, allí el zambaje, en términos de género, era mayoritariamente entre hombres esclavos y mujeres indias ${ }^{16}$. Es decir, muchos zambos nacían en contextos indígenas y asumían la identidad de su madre que era vasalla del rey, vivía en una de las repúblicas y no era esclava. La matrilocalidad se imponía en este escenario; así, la identificación racial del zambo al lado de su ascendiente en los pueblos de indios lo alejaba de la esclavitud.

Pero también la desigualdad de género en las estancias y haciendas esclavistas y el hecho que los que más huían a formar palenques en las gobernaciones en mención eran esclavos del sexo masculino, llevaron de manera frecuente al robo y violación de mujeres indias ${ }^{17}$. En una visita fechada en el año de 1602 a la gobernación de Cartagena se comprueba que las rela-

${ }^{11}$ En el diccionario de la lengua castellana de 1815 aparece una acepción que define al zambo así: «Dícese en Indias del hijo de negro y india, ó al contrario», Diccionario de la Real Academia Española de la Lengua, 1815: 67.

12 Rueda, 2001. Guerra, 1994.

13 Solórzano y Pereyra, 1972: 445.

${ }^{14}$ Cavieres, 2000: 74.

${ }^{15}$ Ibarra, 2007: 105-115.

${ }^{16}$ Ares Queija, 2000: 75-80.

17 Meisel, 1988: 99. 
ciones entre indígenas y negros en el área rural pasaban por ser conflictivas. Se denunciaba que esclavos de varias estancias entraban a los pueblos de indios a «alterar el ánimo» $\mathrm{y}$, específicamente, que en una estancia en el área de Mahates, en uno de sus pueblos de indios, «tres negros... los quales son harrieros» agredían a los indígenas y, en especial, «uno de ellos llamado Sebastián solía ir al pueblo el qual dicho negro lo inquieta y tiene pendencias con el casique y así mismo sabe este testigo que quiso forzar a una yndia nombrada María» ${ }^{18}$. Otro caso habla de un «negro esclavo» que era acusado de estar «mucho tiempo amancebado públicamente con Aldonca yndia, la qual tenía en su servicio del dicho negro...» ${ }^{19}$. Aquí llama la atención la razón que daba Aldonca cuando, según la testigo, ella le increpaba por vivir con el esclavo y «que la dicha le respondía que no se podía apartar del porque le daba de comer». Este robo de mujeres no se daba solo por los esclavos de las estancias sino por cimarrones que también las llevaban a los palenques. Como señala María Cristina Navarrete en la conformación del llamado palenque El Limón, en extramuros de la ciudad de Cartagena, los cimarrones allí ubicados en 1632 robaron mujeres indias de los pueblos cercanos «porque los criollos y criollas del palenque eran todos parientes» ${ }^{20}$.

Por otro lado, por ser de padre africano y madre indígena, no tener rastros hispanos, como si los tenía el mestizo y el mulato y ser de condición ilegítima, el zambo cargó con una imagen negativa a ojos de los españoles, siendo, en ocasiones, comparado con un animal nativo de América. Por ello, clasificar al zambo en el sistema jurídico fue cuestión difícil para las autoridades españolas, de hecho fueron numerosas las consultas sobre su ubicación en términos del ordenamiento social, especialmente frente al tema de sus cargas ${ }^{21}$. Por ejemplo, se indagaba si debían pagar o no el tributo ${ }^{22}$, a lo cual las autoridades consideraron siempre que estos debían sufragarlo igual que los indios cuando vivían con ellos, lo cual da pistas sobre una primera ubicación social del zambo, al ser adscrito en primera instancia a la república de indios. Pero, el zambo en varias ocasiones no se radicó en pueblos de indios y así, como

${ }^{18}$ Gallego Sánchez, 2004: 63-69.

19 Idem.

${ }^{20}$ Navarrete, 2011: 126.

${ }^{21}$ En el diccionario de la lengua castellana de 1729 se define al ciudadano como «El vecino de una ciudad, que goza de sus privilegios y está obligado a sus cargas, no relevándole de ellas alguna particular exención». Diccionario de la Real Academia Española de la Lengua, 1729: 364.

${ }^{22}$ Consulta al virrey sobre si los hijos naturales de negros y mulatos e india debían pagar tributo, 15 de abril de 1806, Archivo General de la Nación, Bogotá (en adelante AGN), Tributos, leg. 16. 
veremos más adelante, obtuvo la condición de emancipado de tributación y de la esclavitud, se volvió libre ${ }^{23}$.

\section{El surgimiento de sitios de gente libre}

Para finales del siglo XVIII la categoría de poblamiento llamada «sitio de libres» designaba en la provincia de Cartagena y Santa Marta «a todo lugar que tenga alguna población aunque corta como no sea ciudad, villa o pueblo de indios» y, en general, su vecindario era racialmente «mixto y común de españoles, mestizos, negros mulatos, zambos y otros de tales mixtiones que tienen sus determinadas denominaciones», los cuales, según el cronista «generalmente se nombran libres por distinguirse de los indios tributarios» y de todos los colores por sus diversas mixturas ${ }^{24}$.

Debemos ahora preguntarnos cómo emergieron pueblos o sitios con la categoría de libres y por qué para el siglo XVIII la mayoría de poblados de la gobernación de Cartagena y Santa Marta tenían esa calidad. Primero analicemos el surgimiento de uno de estos sitios: Chiriguaná, en la gobernación de Santa Marta. Este lugar aparece en un censo realizado en el año de 1793 con 2263 habitantes, siendo la tercera población en número de habitantes de la gobernación después de Santa Marta y Valledupar y con la categoría de $\operatorname{sitio}^{25}$. La fecha exacta de su fundación no se puede ubicar pero si el proceso que lo originó, a partir de un pleito desarrollado durante los años de 1795 y 1806 entre los habitantes del lugar y un importante comerciante de la ciudad de Mompox, dueño del hato de San Antonio del

${ }^{23}$ Por otras vías, un número importante de esclavos se fugaban y se volvían cimarrones; otros, en tanto formaran palenques alcanzaban la libertad de hecho. También un porcentaje importante obtenía la libertad graciosa o manumisión de parte de sus amos. Las libertades que mencionamos, tanto la del zambo, como la legal del esclavo manumitido o coartado y la del fugado, tenían en común que colocaban a estos sujetos en situaciones que los hacían escapar del tributo, por ello fueron llamados de calidad «libres». Dado que la libertad del palenque era subversiva del derecho, no era legal, a estos esclavos huidos se les dio la calidad de cimarrones para denotar que su libertad no era en derecho.

${ }^{24}$ Peredo, 1971: 137. Dado que la mayoría de los libres provenían de la mezcla racial de los colores primarios blanco y negro con indígenas o entre ellos y su mixtura había llegado a niveles irreconocibles, se les envolvió dentro de la frase «de todos los colores», sobre todo cuando se aludía a ellos colectivamente, para así designar una amalgama que contenía diversos linajes raciales. A esta obra llegué gracias a la profesora María Cristina Navarrete.

${ }^{25}$ Tovar, 1994: 504-507. De los 2.263 habitantes que tenía el sitio de Chiriguaná para el año de 1793, eran libres de todos los colores 2.109, es decir más del 94\% de sus habitantes. 
Dividivi ${ }^{26}$. De entrada podemos advertir que en la búsqueda por clarificar los derechos de propiedad en el proceso en cuestión, se reconocía el vínculo directo entre el surgimiento del sitio y la instalación del hato. Así, mientras la unidad productiva se fundó en el año de 1700, la aparición de Chiriguaná se relaciona años más tarde y como fruto del mestizaje, de la llegada de población «libre» de otros sitios y el crecimiento vegetativo tanto de esclavos como concertados del hato. En cambio, el establecimiento del hato se puede asociar a la existencia de un pueblo de encomienda durante el siglo XVII, según lo que atestiguaba un vecino de la ciudad de Mompox en el año de $1802^{27}$.

De los datos aportados en el expediente se entiende que la instalación de la unidad productiva llamada hato ganadero a comienzos de siglo XVIII implicó la presencia de «esclavos, concertados y agregados», que trabajaron en «consorcio» con el «primer fundador del hato», apoyándolo en «los desmontes y limpieza del terreno y defendiéndolo de las invasiones de los indios bárbaros.... ${ }^{28}$. Siguiendo un primer censo del hato de San Antonio del Dividivi, tenemos que este, a comienzos del siglo XVIII, tenía «su capilla en que se celebra el santo sacrificio de la misa, su casa de vivienda de 40 varas de largo, bujios de los esclavos y corrales para los ganados» ${ }^{29}$, más de 8000 reses, 14 esclavos y un número indeterminado de concertados y agregados ${ }^{30}$. Era claro que en las sabanas de Chiriguaná primero se instaló el hato por parte del mencionado Ospino - radicado en la ciudad de Cartagena- y, luego, muchos años después, se formó el sitio «con el nombre de Chiriguaná, con otros que a poca distancia se conocen ahora.... ${ }^{31}$.

En tanto, don Juan Clímaco de Marcos anotaba que el sitio de Chiriguaná tenía «su origen de algunos concertados» de la hacienda del Dividivi, cuyas familias se fueron «agregando a ella y enlazándose con los esclavos de que resultó libertarse algunos con consentimiento de sus amos» y «aquellos se

${ }^{26}$ Pleito entre los habitantes de Chiriguaná y Don Domingo López Bordel por tierras del hato de San Antonio del Dividivi, Santa Fe, 16 de enero de 1795, AGN, Fondo Tierras del Magdalena (en adelante FTM), legajo 132.

${ }^{27}$ En el área donde se ubicó el hato de San Antonio del Dividivi existieron las encomiendas Chingalé, Tomala, Tamalaguaca, Tamalanataca, Simpapoya y Niguas. Mena, 1982: 11.

${ }_{28}$ Preguntas contestadas por Juan Royero, vecino de Chiriguaná al procurador Luís de Ovalle, 19 de Agosto de 1802, AGN, FTM, leg. 132.

${ }^{29}$ Idem.

${ }^{30}$ Preguntas contestadas por Tomás Díaz, vecino del sitio de San Marcos del Paso del Adelantado al alcalde de la Santa Hermandad de la ciudad de Valledupar Joaquín Montaño, Paso del Adelantado, 19 de diciembre 1798, AGN, FTM, leg. 132.

${ }^{31}$ Preguntas contestadas por Mateo de Otero, vecino de Tamalameque, al procurador Luis de Ovalle Díaz, Tamalameque, 22 de septiembre 1800, AGN, FTM, leg. 132. 
fueron multiplicando y poblando sin orden dicho sitio», haciendo sus ranchos donde les convenía y dándoles «el negro capitán de la hacienda licencia para ello, como que eran todos ocupados en los trabajos de ella...» ${ }^{32}$. Tomando «incremento» años más tarde el sitio con la llegada de «familias de todas clases» y de distintos lugares.

Aquí observamos dos elementos importantes favorecedores del mestizaje. En primera instancia la complejidad del establecimiento de unidades productivas en zonas de frontera, donde se debían enfrentar dificultades como los ataques de indios flecheros. En segundo lugar, la presencia temprana de mano de obra libre y por tanto, de población libre dentro del hato mezclándose con los esclavos. Lo uno y lo otro conllevaron a que los dueños de las unidades negociaran o establecieran pactos de reciprocidad con la mano de obra (esclava, concertada y agregada) para garantizar el funcionamiento de estas y su amparo ante el ataque de los indios flecheros.

Llama la atención que este mestizaje fue propiciado por los mayordomos de los hatos, quienes para la historia que narramos eran esclavos con bastante autonomía para definir el futuro económico de la unidad productiva. Este fue el caso de un capitán de apellido Ospino, administrador del hato del Dividivi, quien no sólo controlaba los gastos de la unidad, sino que era amo absoluto de esta cuando no estaban sus dueños, que era la mayoría del tiempo ya que estos estaban radicados en la ciudad de Cartagena. Para el año de 1725 Ospino estaba a «cargo y cuidado» del hato y de una estancia de cacao fundada en las sabanas de Curumaní. A su muerte le siguió el capitán Jerónimo de Ospino, al parecer su hijo, y años más tarde, en 1780, la administración estuvo en manos de Pablo Herrera, también esclavo capitán, quien estuvo a las órdenes de López Bordel, su amo en ese momento.

El fenómeno de unidades productivas administradas por capitanes esclavos fue usual en las gobernaciones de Santa Marta y Cartagena y nos permite observar las relaciones dentro de las unidades con una mayor laxitud de la que hasta ahora se ha visto. De ahí que se señalara al capitán Antón Ospino como el único «a quien obedecían los esclavos, concertados y agregados, como de quien recibían los arbitrios de subsistir» ${ }^{33}$. Al garantizarles su subsistencia, el aludido capitán contaba también con una reserva de hombres que se enrolaban en las entradas que desde el sitio de Chiriguaná se realizaban contra los indígenas ubicados en cercanías al hato, como ya anotamos.

Vemos entonces que una de las vías para la conformación de los pueblos de libres fue el mestizaje vinculado a las dinámicas que se desarrollaban en

\footnotetext{
32 Idem.

33 Idem.
} 
las haciendas esclavistas y los hatos ganaderos ${ }^{34}$. Bajo esta perspectiva entendemos porque estos sitios se encontraban cerca o en los bordes de estas unidades productivas y el establecimiento de pactos de reciprocidad entre los hacendados y sus mayordomos esclavos y entre estos y la población concertada y agregada. Cuestión que revela un entramado de relaciones económicas y muestra a los libres articulados con las unidades productivas en el mundo rural, rutas de transporte de mercancías a los mercados locales y, como milicianos, atacando a los indígenas flecheros que destruían dichas unidades.

Entremos ahora al tema de los palenques. Sabemos que la agrupación o agregación de negros cimarrones en los llamados palenques fue criminalizada con penas que iban desde la destrucción del sitio hasta el arresto y ejecución de sus habitantes en tanto se comprobara su sublevación y lazo legal de esclavitud. Pero, aquí también surgen ciertas singularidades. En ocasiones algunos palenques fueron destruidos y arrasados después de más de cincuenta años de existencia, lo que colocó a sus habitantes en un universo ambivalente en términos de su status ante el derecho; por un lado, muchos de los negros eran hijos de esclavos fugados que habían muerto, lo que hacía que no se supiera quienes fueron sus amos y, tampoco existían españoles que reclamaran ese derecho. En tanto, los hijos de las mujeres indias que fueron llevadas a los palenques, ahora zambos, eran considerados libres.

Todo lo anterior, unido a la debilidad y ambivalencia de las autoridades del cabildo de Cartagena y los funcionarios reales frente al tema de si era procedente la destrucción de los palenques o la negociación con los cimarrones, llevó a que las autoridades reales y eclesiásticas optaran por la vía de la negociación con estos, su integración a la vecindad, como veremos enseguida.

El 9 de diciembre de 1713 el obispo de Cartagena Antonio María Cassiani comentaba que en cercanías a Turbaco se le habían acercado «diez mujeres cabezas de sus castas» con el capitán «de todas ellas apedillando en rendimiento, paz y reducción» $\mathrm{y}$, le declararon «ser individuos de un numeroso común de esclavos cimarrones, que fugitivos de sus dueños» se habían «retirado, (días había) a las montañas, a hacer habitables sus malezas con la fundación de un palenque en el cerro de María, nombrado San Miguel ${ }^{35}$. Estos, comentaba el obispo en plan de negociación le habían contado que iban «resueltos y arrepentidos a mudar de vida en nueva población» y vivir «en ella cristianamente a nuestra pastoral sombra, y debajo del suave y recto

\footnotetext{
${ }^{34}$ En la jurisdicción de la ciudad de Tamalameque, donde se ubicaba el sitio de libres de Chiriguaná también habían surgido al amparo de los hatos los sitios de San Marcos del Paso del Adelantado, Calenturas y Chimichagua.

35 Martínez, 1986: 390.
} 
dominio de V.M...» ${ }^{36}$, razón por la cual solicitó al gobernador de la provincia de Cartagena que aprobara la reducción de estos cimarrones en sitio regulado por las autoridades civiles y eclesiásticas.

En tanto el gobernador de Cartagena Jeronimo Badillo en ese mismo mes de diciembre de 1713 aprobó la reducción y expidió varias providencias donde regulaba la inserción de los ahora negros libres al vasallaje y la cristiandad. Allí consignó que «los negros, así criollos de la montaña, como de varias castas, que hoy se hallan en el Palenque, han de recogerse en paraje cierto y seguro; el que acordare yo, debajo de una campana, haciendo constar por memoria y padrón fiel y legal, los nombres de todos cuantos quisieren gozar de este beneficio» ${ }^{37}$. Igual señaló que los capitanes de los negros debían comprometerse con varias cuestiones, por un lado que «en dicha montaña de María ni en otra ninguna parte de esta provincia inmediata a ella, en distancia de diez leguas, quede palenque alguno, rancho ni habitación de dichos negros...», también que «el paraje o sitio, donde han de vivir y laborar, ha de ser en tierra libres, sin perjuicio de terceros, las cuales se señalara $\rangle^{38}$. A las anteriores disposiciones seguían otras más precisas como que el sitio debía ser administrado por un «hombre blanco», hacer «iglesia y mantener cura, señalándole salario...»y entregar los esclavos cimarrones, por lo cual recibirían 20 pesos y, en general evitar que «no se avecine, ni haga buhio, español alguno ni mulato, ni otra gente ${ }^{39}$. En compensación podían los habitantes del sitio cultivar las tierras aledañas a este, llevar sus productos a Cartagena y, los que tenían traza de esclavitud, con el fruto de sus «rozas» podían pagarse a sus antiguos amos. Pero, la muestra más grande de magnanimidad estaba en la disposición que determinaba que «los que hubieren ya veinte años que están en el monte sin sujeción de sus amos, estos se reputan ya y quedan libres, sin que por ellos se haya de pagar cosa alguna». Ahora, los cimarrones pasaban a ser libres y labradores, habitantes de un sitio y feligresía de libres, sellándose así una negociación que garantizaba que, de ahora en adelante, serian «tratados por el gobernador, como vasallos de V.M., como todos los demás lugares» ${ }^{40}$.

Veamos otro caso similar que se desenvuelve en las goteras de la ciudad de Santa Marta. En el año de 1700 el gobernador Alonso Valera recogió de los montes cercanos a Riohacha «toda una colonia de negros cimarrones, de ambos sexos y de todas edades, que estaban sin bautizar» y procedió a ubi-
36 Idem.
37 Idem.
38 Idem.
39 Idem.
40 Ibidem: 393. 
carlos a las orillas del río Don Diego en un sitio llamado Guachaca. Allí se establecieron y hasta el año de 1712 estuvieron bajo el control de la ciudad de Santa Marta, a la cual proveyeron con los maíces que cultivaban. Sin embargo, en este último año se presentó una situación cuyo desenlace llevó al abandono del poblado por parte de sus habitantes. Según las versiones de los negros libres el abandono de sus habitaciones y maíces fue motivado por el pleito sostenido con el cura del sitio ${ }^{41}$. La razón del conflicto y el motivo de la protesta se encontraban en el maltrato del cual fueron objeto tres de ellos, al ser azotados cuando estuvieron en la ciudad de Santa Marta visitando al cura. Estos cuentan que, una vez humillados, regresaron al sitio y junto con toda la comunidad decidieron abandonarlo «con tanta hidalguía que no quisieron cargar ni sus maíces ni el moblaje de las casas; la casa cural la dejaron bien limpia y aseada y sobre el altar de la iglesia colocaron las limosnas de la cofradía, la bengala del capitán y el real título de $\mathrm{S} . \mathrm{M} \gg{ }^{42}$. El sitio de Guachaca tenía, a esa fecha, iglesia, cura asignado, cofradía y cumplía un rol estratégico en términos militares de contención de piratas y negros cimarrones a medio camino entre Riohacha y Santa Marta, como lo comprueba la bengala que poseía su capitán. Al igual que San Basilio de Palenque, se insertó a la calidad de sitio vía clero secular y participaron activamente de esta integración como vasallos de la corona española.

Tenemos que la eclosión de los pueblos de libres llevó a las autoridades reales a su reconocimiento en la escala político administrativa y, esta inclusión, aunque en estos momentos precaria, denotaba ya una articulación a la vecindad y al vasallaje, ya sea por la presencia de un cura, por su visibilidad pública o por estar cerca de la tutela de cabildos, capitanes aguerra y hacendados a los que pagaban arrendamiento por el uso de las tierras. El sitio de libres se alinderó jerárquicamente detrás de la villa y al lado de los pueblos de indios en términos político administrativos ${ }^{43}$. Como característica de poblamiento vemos que estos, a diferencia de las «rochelas» como lo revelaremos más adelante, se ubicaban de manera estratégica en los bordes de los hatos y haciendas, a orillas de caminos y arterias fluviales y eran el reservorio de mano de obra que movía unidades productivas, las canoas que llevaban las mercancías de Cartagena al interior del Nuevo Reino y realizaban diversos trabajos artesanales cuando se ubicaban a orillas del río Magdalena.

\footnotetext{
${ }^{41}$ Restrepo Tirado, 1974: 314-316.

42 Idem.

${ }^{43}$ Hay casos documentados de pueblos de indios que pasan a la categoría de sitio de libres dado en ellos se asentaron zambos y negros libres que se mezclaron con las mujeres indias, ver Herrera, 2006: 248-267.
} 


\section{De los libres que vivían en «rochelas»}

Veamos ahora el fenómeno de los hombres y mujeres libres que vivían en «rochelas». Por lo general una rochela era el lugar donde unas personas se reunían, construían bohíos, tenían pequeños cultivos (rozas) en la espesura de los montes, orillas de ciénagas, ríos y caños. En su mayoría se habían formado «de los desertores de la tropa, de la Marinería, de los polizones o llovidos» y de los «negros y indyos cimarrones, o prófugos» los cuales se habían diseminado «por aquellos bosques y asperezas, unos para libertarse del castigo y otros de la sujeción» y al mezclarse «con las negras y indias, procrearon y propagaron la mucha diversidad de castas y colores $\gg{ }^{44}$. Cuando estos grupos de personas de «todos los colores» se ubicaban en lugares específicos, se arrochelan, se alejaban de la vecindad, perdían la calidad de vasallos y, al no tener cura, estaban cercanos a la idolatría y presos de sus instintos mundanos. En este sentido, las «rochelas» son más cercanas a la supuesta anarquía de un estado de naturaleza que encontraba asidero en el territorio, sin las pautas urbanísticas del modelo castellano de la cuadricula y la plaza estilo damero y sin iglesia.

En una entrada contra un grupo de cimarrones en cercanías de la villa de Tolú en la década del treinta en el siglo XVII, el gobernador de Cartagena Pedro Aguilera encontró una agregación o rochela y capturó a veintiuno de sus pobladores, miembros de varias familias compuestas por seis hombres mayores de quince años, seis menores y nueve mujeres. Los capturados, entre ellos «dos negras viejas» señalaban que el poblado se había sido edificado hacia cincuenta años cuando ellas, siendo muchachas habían sido «robadas a los cargadores que las llevaban desde Angola ${ }^{45}$. Estas veintiuna personas vivían en catorce bohíos sin ninguna defensa y junto a ellos se encontraban ocho indios y una niña zamba. En uno de los bohíos se encontró bastante miel, maíz y pieles y otros objetos. Este sitio era, a todas luces, una rochela.

Pero son las descripciones del padre Joseph de la Vega a finales del siglo XVIII las que nos detallan las particularidades del fenómeno de las «rochelas» ${ }^{46}$. Al igual que en el anterior retrato, tenemos nuevamente la cuestión de las mujeres robadas. Una de cuatro mujeres encontradas en una «rochela» en cercanías a la villa de Ayapel le contó la forma en que el «zambo» con quien vivía la había robado al «sacarla al medio de la ciénaga y que allí la desfloró»» ${ }^{47}$. Otra

\footnotetext{
${ }^{44}$ Herrera Ángel, 2002b: 16.

${ }^{45}$ Ruiz, 1990: 25.

46 Para casos parecidos en Venezuela ver Waldron, 1991: 173-196.

47 Palacios, 1994: 55.
} 
mujer señalaba que una vez instalada en la rochela había tenido dos hijos que «habían muerto sin bautismo y sus cadáveres tirados a las ciénagas» ${ }^{48}$; y confesaba tener más de seis años de no ir a misa. En tanto una tercera a la pregunta sobre cuál de los cuatro hombres que habitaban la rochela era su esposo respondió que «ella no tenía ninguno y que todos pecaban con ellas y las otras $\rangle^{49}$. En otra rochela cercana de la Vega encontró varias mujeres, de las cuales «tres eran casadas que se huyeron de sus maridos por venirse con aquellos onbres»y otras «ya eran mujeres con hijos de sus propios padres» ${ }^{50}$.

Ya en sus habitaciones descubrió que en un rancho de paja «dormían todos juntos en el piso» dándose el caso de que «tres rianos dormían con siete mujeres», y «otros con sus propias hijas, otros con sus propias hermanas y madres» ${ }^{51}$. Alrededor y dentro de las viviendas las mujeres «sin camisa andaban» y todo su «ajuar era unas maguas de listado azul sin más camisa y menos enaguas blancas y las criaturas en cueros» rodeadas de «una olla y tres camas de chonta sin una estera ni almohada» mientras que las ancianas vivían «sentadas en unas ojas de plátano, de edad como de setenta u ochenta años, su color mulatos, sin más ropa que una trapo en la cintura con unos pollitos alrededor» ${ }^{52}$. Mientras que los varones se dedicaban a la pesca, boga, contrabando, robo, la caza y al cultivo de rozas de maíz, yuca, arroz, ñame y tabaco y andaban semidesnudos con «un vangaño colgado al hombro, una estera y un machete» ${ }^{53}$.

Su pobreza material era elocuente. En el interior de los ranchos solo encontró «una mesita en medio, una cruz, una mecha con aceite de caimán y una totuma con agua y algunas esteras». El cura percibía que estas gentes levantadas «contra todo orden superior» eran «sumamente infelices, pues la mayor parte de su producción constaba de almud y medio de maíz, otro tanto de arroz y varios pies de yuca ${ }^{54}$. En realidad estas pequeñas rozas permitían a los arrochelados sobrevivir y llevar excedentes a mercados locales o a las haciendas agrícolas y ganaderas cercanas a las «rochelas».

En general, advertimos que las «rochelas» condensaban una vida en estado de naturaleza puro. Mujeres robadas, cimarrones, bandidos y otros se asentaban en las breñas, en montes y vivían lejos de Dios y del vasallaje. Perseguidos o no, el modo de vivir arrochelado fue criminalizado en la segunda mitad

${ }^{48}$ Ibidem: 56.
49 Ibidem: 57.
${ }^{50}$ Ibidem: 58.
${ }^{51}$ Ibidem: 59.
${ }^{5}$ Ibidem: 62.
${ }^{53}$ Ibidem: 63.
${ }^{54}$ Ibidem: 64.

Revista de Indias, 2015, vol. LXXV, n. ${ }^{\circ} 264,457-488$, ISSN: 0034-8341

doi:10.3989/revindias.2015.015 
del siglo XVIII, sobre esta heteróclita población se centró la mirada de los portadores del discurso reformador borbónico, para quienes en el nuevo concepto de Estado que portaban no tenían cabida, en cuanto no aceptaran vivir en policía, bajo la ley y el orden.

Hasta aquí un panorama general del mestizaje y sus implicaciones en términos del derecho nos explicaría, a largo plazo, el problema del surgimiento de los sitios de libres y «rochelas» ${ }^{55}$. En tanto la búsqueda de libertad por parte de los esclavos nos explicaría el surgimiento de palenques ${ }^{56}$.

\section{ORDENAR PARA INCLUIR}

Luego de salir victorioso en la defensa de la ciudad de Cartagena ante el asalto ingles de 1741, el virrey Sebastián de Eslava decidió, instruido desde Madrid, introducir cambios en lo que él consideraba debían ser las relaciones esta ciudad y parte de su hinterland ${ }^{57}$. Fue así como en el año de 1743 el virrey Eslava mencionaba que era necesario colocar en regla «el modo de vivir de la gente libre de la Provincia de Cartagena, Santa Marta» y «márgenes del río Magdalena», ya que «divididas las familias en el dilatado espacio de cada parroquia» y formando «sus casas en el monte que les parecía más cómodo, carecían de todo pasto espiritual», de la «subordinación al cura y a la justicia», viviendo disolutamente «que no había exceso que no cometieran, sin poderlos contener... $\rangle^{58}$. Esa forma de vivir en supuesto estado de barbarie no podía permitirse y debía ahora reglarse por el derecho y por el Estado.

Fue así como se inauguró la criminalización de los «libres de todos los colores» en las gobernaciones de Cartagena y Santa Marta que vivían en «rochelas» y, se emprendieron acciones para volverlos vasallos, cristianos y vecinos al buscar ubicarlos en sitios específicos donde contribuyeran a la defensa de la ciudad de Cartagena, cerca de las rutas comerciales y caminos por donde

${ }^{55}$ Como bien señala Lucena Giraldo, para el siglo XVIII, aparecen en la América Hispana en los términos de las ciudades fundadas en la conquista una «multitud de pueblos, junto a estancias y haciendas en formación y otras comunidades no oficiales pero más o menos toleradas. Se trataba de campamentos y rancherías de mineros, llaneros y otros supuestos ladrones de ganado, cumbes y palenques, esclavos huidos o rochelas, núcleos de campesinos pobres y libres, zambos, mulatos, mestizos, blancos y negros todos tácitamente aceptados porque lo fundamental era que acataran la autoridad real y también porque no había otro remedio». Lucena, 2006: 3.

${ }^{56}$ Borrego, 1973.

57 Kuethe, 1993. McFarlane, 1997.

58 Colmenares, 1989: 50. 
circulaban ganados y alimentos y como milicianos que debían participar en las entradas contra los indígenas belicosos que atacaban haciendas, pueblos y viajeros. Para ello se tomó la figura del «sitio» como lugar donde debía operarse la integración, allí, agrupando varias «rochelas» o «arrochelados» se les dotaba de institucionalidad. De operarse dicha política, los libres ahora harían parte de la republica de españoles y, al igual que los indígenas borrarían con sus acciones el estigma racial que los acompañaba al ser producto de mezcla ilegítima ${ }^{59}$. Eslava hacia suyas las palabras de Solórzano quien previendo la emergencia de los mestizos, señalaba que «si estos hombres hubiesen nacido de legitimo matrimonio, y no se hallasen en ellos otro vicio, o defecto que lo impidiese» podrían, a futuro, «contarse por ciudadanos de dichas provincias, y ser admitidos a las honras y oficios de ellas como lo resuelven Victoria y Zapata.... ${ }^{60}$ y fue más allá, eludió, convenientemente, el tema de la ilegitimidad de los libres al no ser estos bautizados o fruto de matrimonios católicos.

Para lograr esta empresa Eslava concibió un plan que, teniendo en cuenta la escasez de recursos fiscales, fuera apoyado por una clase de empresarios que, a la luz de las mismas reformas, se beneficiaban del reordenamiento administrativo ya que necesitaban mano de obra libre en sus haciendas y hatos ganaderos y hombres que movieran tanto carnes como mercancías a los mercados. Fue así como en el mes de octubre de 1743 el virrey Eslava, por estar informado de «los servicios» prestados a la Corona en el sitio de la ciudad de Cartagena en $1741^{61}$ por el español, radicado en la ciudad de Mompox don Fernando de Mier y Guerra, revalidaba las prerrogativas que, inherentes al título de Maestre de Campo había dado el gobernador de Santa Marta Juan de Vera en $1739^{62}$. Agregaba a estas disposiciones un nuevo elemento, aparte de organizar milicianos para una eventual defensa de la ciudad, ahora debía «ocuparse en nuevos descubrimientos y poblaciones» en la gobernación de Santa Marta ${ }^{63}$.

${ }^{59}$ Como señala Tamar Herzog en América se operó un cambio al flexibilizarse las calidades de los vecinos a finales del siglo XVII y comienzos del XVIII, en adelante «En vez de clasificar a las personas según su ascendencia, ahora se las clasificaba también en virtud de su residencia y su actuación. Estos cambios apuntaban a una posible homogeneización de ambas repúblicas. Sugería la aparición del vecino como una categoría de persona que, independiente de su origen y etnia podía elegir su lugar de residencia y convertirse, a través de sus acciones y su reputación, en miembro de una comunidad». Herzog, 2006: 82-83.

60 Solórzano y Pereyra, 1972: 447.

${ }^{61}$ Marchena Fernández, 2005: 21.

${ }^{62}$ Ratificación del título de Maestre de Campo a don Fernando de Mier por parte de don Sebastián de Eslava, Santa Fe, 26 de Octubre de 1743, AGN, Fondo Milicias y Marina, leg. 32.

${ }^{63}$ Real Cédula dándole facultad para realizar nombramientos para pacificaciones y descubrimientos al virrey don Sebastián de Eslava, Madrid, 20 de agosto de 1739, AGN, Reales 


\section{Los libres se insertan a la vecindad, la milicia y el mercado}

Así, primero Eslava dio comisión y facultad a Mier para que en derecho, por «sí y las personas que eligiere de su confianza, pueda obligar a toda la gente libre» y «vaga de uno y otro sexo, de cualquier calidad y condición que sean, a que residan en sociedad.... ${ }^{64}$. Luego Mier nombró a unos capitanes que debían ayudarle en la mencionada congregación y, si se quiere, encargarse de las nuevas fundaciones. Estos, tenían facultad para ir a los cabildos de las ciudades en cuyos términos se establecerían los sitios, informar sobre sus acciones a las autoridades locales, para luego proceder a escoger el lugar donde iban a realizar una fundación y proceder a recoger las personas que debían habitarlo. También tenían poder para agregar varias «rochelas» a un pueblo principal, posiblemente un sitio ya poblado o procedían a trasladarlos a una nueva fundación. A diferencia de la integración vía clero secular a comienzos de siglo XVIII que operó con los palenques y que solo se hacía en términos de la construcción de la iglesia, ahora, un sitio adquiría un estatus de integración mayor cuando se le construía una plaza, cárceles, se le dotaba de justicia a través de un capitán aguerra y se constituía una cofradía advocación al patrono del sitio - por lo general era el de su nombre- y se le adjudicaban terrenos comunales para garantizar que los habitantes tuvieran donde producir sus alimentos y llevar excedentes a los mercados comarcanos.

Un área geográfica sobre la cual el maestre de campo y sus enviados centraron sus acciones fue en cercanía a la ciénaga de Zapatosa y la desembocadura del río Cesar, en los extramuros de la ciudad de Mompox cerca de dos hatos ganaderos que Mier tenía allí establecidos: el de Carrera Larga y el de Calenturas y cerca de otros hatos como el mencionado de San Antonio del Dividivi ${ }^{65}$. Fue así como los procesos de poblamiento se iniciaron en el año de 1746 y, para el año de 1748, éste informaba que había fundado y agregado

Cedulas, leg. 9. En general Mier tuvo presencia política y económica durante más de quince años sobre la banda derecha del río Magdalena entre la ciudad de Tamalameque, la desembocadura del río Cesar sobre la ciénaga de Zapatosa y su desembocadura en el mar Caribe, territorio que coincidía con la jurisdicción de las ciudades de Valencia de Jesús, Tamalameque y la villa de Tenerife. Abrió caminos, trasladó pueblos, adjudicó terrenos, movilizó personas, realizó y financió entradas contra los chimilas, nombró jueces, recogió vagos y desertores, sembró trigo en la Sierra Nevada de Santa Marta, enfrentó los poderes locales, ayudó al incremento del comercio, cárceles, trazó calles y dotó de pasto espiritual a un número aproximado de veinte y dos pueblos y sitios en la gobernación de Santa Marta y expandió sus hatos ganaderos. Al respecto ver: Tovar, 1980: 45-68.

${ }^{64}$ Virrey sobre las acciones de Mier, Santa Fe, 10 de Abril de 1748, AGN, Empleados Públicos de Bolívar, leg. 31.

${ }^{65}$ Tovar, 1980: 34. 
población libre en los sitios de Santa Bárbara de Tamalamequito, Nuestra Señora del Carmen de Barrancas de Guamal, Nuestra Señora de la Candelaria de El Banco, Menchiquejo, San Sebastián de Buenavista, San Vicente Ferrer de Saloa y Nuestra Señora de la Concepción de Chimichagua, éstas dos últimas poblaciones en cercanías a los dos hatos mencionados anteriormente. Hasta aquí encontramos que seis de las siete poblaciones existían como parroquias o agregaciones de libres y solamente San Vicente Ferrer de Saloa resultó de una congregación de «tres sitios o rochelas que son Sapatí, Zapatosa y Empalagado» ${ }^{66}$. Es decir, legitimó sitios que ya existían y a ellos agregó alguna población. El proceso no excluyó la violencia, en lo que se refiere a Empalagado, Mier ante la negativa de trasladarse de sus habitantes, que en su mayoría eran zambos y mulatos, procedió a quemar sus ranchos y bohíos.

Ya en el año de 1748, desde Cartagena, el virrey Eslava le escribía a Mier aprobando su gestión de congregación de sitios y felicitándolo porque «vuestra merced hubiese dispuesto la fábrica de cárceles, iglesias y plaza» para estos, por lo cual, ahora, le daba autorización para que le propusiera «por esta vez los sujetos que considerare más a propósito para el nombramiento de alcaldes pedáneos de cada parroquia o población, a fin de librarles el título correspondiente...» ${ }^{67}$. Fue así como Mier hizo nombrar como curas párrocos, alcaldes y capitanes aguerra de las nuevas poblaciones a personas cercanas a su entorno clientelar. Por ejemplo, a las poblaciones ubicadas entre Mompox y Chiriguaná les nombró a Antonio Ruidíaz como su capitán aguerra, en tanto el sargento Tomás de Antique se encargó de impartir justicia en las poblaciones ubicadas en el bajo Magdalena. En el campo espiritual solicitó y recibió el apoyo de los curas capuchinos fray Francisco Labata y Buenaventura de Murcia, quienes con varios acólitos se movían en las fundaciones realizadas.

A cargo de los capitanes, ahora alcaldes pedáneos o capitanes aguerra, estuvo la activación de deberes para los libres -ahora avecindados- en la esfera miliciana. Esto, porque Mier se comprometió con Eslava a mantener «milicias alistadas y arregladas por compañías con los oficiales correspondientes» en la villa de Mompox, ante un eventual ataque a la ciudad de Cartagena, la «plaza capital». De no haber ataque los milicianos ahora ubicados en estos sitios debían acudir, liderados por el alcalde o capitán aguerra, sus sargentos y capitanes, a los parajes por donde «intentaren los enemigos de la corona hacer alguna invasión ${ }^{68}$. Hasta aquí se observa que el rol de Mier se insertaba

\footnotetext{
${ }^{66}$ Mier, 1987: 172.

${ }^{67}$ Certificación sobre actuaciones de Mier, Santa Fe, 23 de febrero de 1748, AGN, Empleados Públicos de Bolívar, leg. 3.

${ }^{68}$ Idem.
} 
en la política de defensa que esbozaba Eslava después del ataque inglés de 1741. Al no existir un ataque externo Mier y los milicianos terminaron actuando contra los llamados indios infieles que obstaculizaban el transporte de mercancías por el río Magdalena y de carne de los hatos ganaderos ubicados en los términos de la ciudad de Tamalameque y Valledupar a Cartagena. Fue así como de manera conjunta, desde estos sitios de libres, pueblos de indios y ciudades (Valencia de Jesús, Mompox y Santa Marta) salieron combatientes que realizaron correrías durante varios años hacia el territorio de la llamada nación chimila y fueron los que lograron debilitarlos y alejarlos de las orillas del río Magdalena y de los hatos ganaderos que empezaban a establecerse para la época entre la ciudad de Valledupar y Mompox ${ }^{69}$. Mientras que en las ciudades portuarias, temiendo al ataque inglés, se establecían las milicias disciplinadas y su interior las compañías de pardos y morenos. En adelante las armas del rey estarían en manos de los «libres de todos los colores» ${ }^{70}$.

Una vez insertos los libres en las milicias, con cura y autoridad civil, sobreviene el tema de vincularlos a los mercados agropecuarios, específicamente en el abasto a la ciudad de Cartagena. Es por ello que después de cada fundación o refundación que realizaba Mier, este justificaba los traslados argumentando que una vez los «libres de todos los colores» estuvieran asentados en sitios específicos ayudarían a incrementar la producción agropecuaria y fortalecerían la producción local. Por ejemplo, de los primeros pueblos que aglutinó señalaba que quedaron ubicados a orillas del río Cesar, en el puerto de Saloa, desde donde se hacía «medio entre Chiriguaná y el río grande de la Magdalena donde logran sus moradores la navegación y comercio por dicho río Cesar para El Paso de Adelantado y Chiriguaná»>11. Así, se garantizaba una vía expedita para el comercio y el traslado de carnes saladas desde su hato ganadero y los hatos ubicados en las sabanas de La Jagua, El Paso del Adelantado, Calenturas y Chiriguaná a la ciudad de Mompox y Cartagena. También, se controlaban «los mejores playones para la cría y engorde de ganados mayores», donde él tenía sus ganados.

Por ejemplo, de la fundación del sitio de Guamal expresaba su importancia por su posición estratégica sobre el río Magdalena al estar en «terreno alto, libre de inundación, oportuna tierra de labor y pasto» ${ }^{72}$. En cuanto a la población de San Sebastián de Buenavista, la cual estaba situada en la banda

\footnotetext{
${ }^{69}$ Herrera, 2002c: 29-96.

70 Kuethe, 1971: 105-117.

${ }^{71}$ Informe de Mier sobre cinco fundaciones nuevas, Santa Fe, 3 de febrero de 1748, AGN, Miscelánea, leg. 55.

${ }^{72}$ Idem.
} 
oriental del río Magdalena, frente a Mompox, privilegió su refundación por su posición estratégica para el tráfico de ganados y por estar ubicada «sobre el mismo río grande y también sobre el caño de Menchiquejo, es su terreno muy fértil, libre también de inundación y cómo para vender los frutos, por la cercanía que tiene a Mompox $\rangle^{73}$. Así, en los informes dados por Mier al virrey Eslava y a Pizarro dejaba claro que las fundaciones debían traer a futuro un incremento de la ganadería y de la agricultura.

\section{Tierras para vasallos leales a la corona}

Para lograr el incremento agropecuario era necesario dar a los libres derechos de propiedad, así estos fueran comunales. No es que en las «rochelas» no se producían dichos granos, es que varios factores intervenían negativamente en su productividad; por un lado, al no tener calidad de ciudadanos los libres eran víctimas de especuladores, decomisos y obligados a pagar terrajes y arrendamientos cuando se ubicaban en los bordes de los hatos o haciendas de trapiche. Antes de que Mier apareciera en el escenario estos usaban la tierra sin tener ningún sustento legal, ahora había que dotarlos de derechos de propiedad. Mier procedió a legalizar este acceso a tierras comunales a nombre del Rey y estableció con ello una especie de pacto de reciprocidad que daba a los libres la posibilidad de usar tierras sin el temor a ser desalojados, ver destruidas sus rozas, quemadas sus casas y eximidos del pago de arriendos por uso de tierras.

Fue así como en 1747, autorizado por Eslava, Mier ordenó a sus comisionados que procedieran a repartir «las tierras realengas que hubieren en la circunferencia» de los poblados, con el fin que tuvieran «donde labrar y pastar sus ganados»; añadiendo que sobre estas podían hacer usufructo «sin pensión de pagar interés alguno a su majestad por razón de dichas tierras» ${ }^{74}$. Veamos el proceso de adjudicación de tierras al sitio de libres de Guamal. Allí, Mier, a los 13 días de julio de 1748 reunió a los vecinos del sitio y les dio "posesión de las tierras que expresa el superior despacho las cuales debían de ser comunes entre todo el vecindario y enajenables como si propiamente fueran ejidos, ni en ningún tiempo puedan poner cosa alguna en perjuicio del común, porque entonces las tierras las tendría S. M. como si fuera una legua

\footnotetext{
${ }^{73}$ Idem

${ }^{74}$ Adjudicación de tierras a los vecinos de Nuestra Señora del Carmen de Barrancas de Guamal, Santa Fe, 5 de julio de 1748, AGN, FTM, leg. 132.
} 
de resguardo» ${ }^{75}$. En la ceremonia de repartimiento de las tierras al común los delegados por Mier leían un documento expedido por uno de los procuradores de número de la Audiencia de Santa Fe, donde se informaba a los libres que por orden del virrey se les daba «una legua de terreno realengo para sus labores y pastos sin pensión de pagar interés alguno a $\mathrm{S}$. M. en premio de sus servicios en haber ayudado a exterminar los indios bárbaros chimilas» ${ }^{76}$.

Los efectos de este proceso se perciben años más tarde cuando el 16 de marzo de 1780, ante don Martín Ruiz Díaz, capitán de milicias y juez ordinario del sitio de Guamal, compareció Josef Manuel Oliveros, teniente de milicias de ese pueblo pidiendo posesión sobre las mencionadas sabanas de Nicajo ubicadas en cercanías de la ciénaga de Chilloa $^{77}$. A esta composición se opusieron varios vecinos del sitio de Guamal, quienes argumentaban que esta era una invasión de sus terrenos comunales, los mismos que había asignado Mier en el año de 1748. En un apretado resumen del litigio tenemos que los primeros pobladores que asistieron a la ceremonia de entrega de tierras en el año de 1748, acusaban a los que querían establecer allí nuevas unidades productivas de no haber participado de las entradas contra los chimilas, es decir no tenían la calidad de conquistadores, por ello tampoco tenían derechos de propiedad comunal. Al final encontramos que en el año de 1799 se les ratificaba el derecho de propiedad a los primeros pobladores por parte de un fiscal de la Audiencia de Santa Fe. En resumen vemos como los vecinos de Guamal salían a defender y validar sus derechos sobre las tierras que recibieron en 1748 , que consideraban eran comunales, por lo cual no podían componerse, como pretendió Oliveros ${ }^{78}$.

Pero hay un caso que llama la atención por el conflicto que originó, su duración y el número e importancia de los actores que allí se vieron involucrados. Santa Cruz de Pizarro fue una de las poblaciones que aglutinó Mier y Guerra a orillas del río Magdalena, a la altura de su desembocadura y donde enfrentó el peor de sus conflictos con otros hacendados igual de poderosos a él. Allí se presentó una pugna con varios vecinos del sitio de Soledad quienes, liderados por Miguel Téllez Camacho, argumentaban que tenían derechos de propiedad sobre las tierras dadas por Mier a los habitantes de Santa Cruz. Esta reclamación, vincularía a Mier y sus lugartenientes, el mencionado Miguel Camacho, sus socios del sitio de Soledad, los habitantes de Santa Cruz, las

\footnotetext{
${ }^{75}$ Idem.

${ }^{76}$ Idem.

${ }^{77}$ Los vecinos de Guamal se quejan de invasión de sus tierras, Guamal, 30 de marzo de 1780, AGN, FTM, leg. 137.

${ }^{78}$ Idem.
} 
autoridades fiscales y eclesiásticas de Cartagena, las autoridades de Santafé y uno de los funcionarios más poderosos de Cartagena -quien tenía propiedades en el área- don Andrés de Madariaga, en un extenso pleito que duraría más de una década y generaría un voluminoso expediente.

Por la lectura del proceso sabemos que los vecinos de Soledad sostenían que el virrey Sebastián Eslava en el año de 1743 les había dado derechos sobre tierras en la margen derecha del río Magdalena. Fue así cómo, relata Buenaventura de Murcia - comisionado de Mier para dicha fundación-, después de rozado el plan de la fundación apareció don Miguel Téllez Camacho diciendo que las tierras eran suyas y exigió el fin de los trabajos de construcción de los ranchos de paja ${ }^{79}$. La información dada por Murcia alertó al maestre de campo Fernando de Mier, quien pidió al virrey Pizarro se sirviese ampliarle «facultad para que conceda a los pobladores de Santa Cruz de Pizarro las tierras que necesiten para su subsistencia», incluyendo algunas que tuvieran «dueños particulares» ${ }^{80}$, a los cuales proponía se les remunerara, para así evitar confrontaciones posteriores. Unas semanas atrás Mier ya se había encargado de enviar una misiva a Téllez Camacho solicitándole la donación de dos caballerías de tierras, las cuales estaban ubicadas en cercanías al plan central de la población de Santa Cruz lo que confirma la versión de los vecinos de Soledad. Supuestamente, según Mier, Téllez Camacho aceptó el trato, pero sus herederos argumentarían, años después, que la donación se había realizado por presiones del maestre de campo. También, observamos que Murcia había pactado con Téllez una negociación antes de la fundación para permitirla y que la presión del hacendado Andrés de Madariaga lo había hecho desistir. Téllez se encontraba en mitad de dos poderosos notables de la gobernación de Cartagena, aunque al parecer, tuvo mayor ascendencia sobre él, don Andrés de Madariaga conde de Pestagua.

Volviendo al año de 1751, fecha de fundación de Santa Cruz, encontramos que Mier sabía de los movimientos expansionistas de Madariaga y de su alianza con Francisco de Vargas, vecino notable del sitio de Soledad, quienes ejercían poder e influencias sobre las poblaciones situadas en la margen izquierda del Magdalena y poseían tierras en su margen derecha, hacia donde estaban extendiendo sus hatos ganaderos ${ }^{81}$. Así, los vecinos de Soledad argumentaban que ellos habían poblado primero los terrenos que se habían adjudicado a Miguel Téllez Camacho, razón por lo que la donación que este había hecho a Mier

\footnotetext{
79 Proceso por destrucción del sitio de Santa Cruz de Pizarro, Soledad, 4 de febrero de 1751, AGI, Santa Fe, leg. 1168.

${ }^{80}$ Idem.

81 Tovar Pinzón, 1980: 55.
} 
era imperfecta ${ }^{82}$. Al final, para el mes de enero del año de 1756 saldría a la luz pública que estas tierras eran realengas y cómo Camacho, a sabiendas de lo anterior, las había arrendado a los vecinos de Santa Cruz y de otro sitio llamado Carmona, por lo cual se le abrió un juicio fiscal que buscaba que los dineros cobrados por este como arriendo desde 1746 debían ingresar a las cajas reales. Allí mismo se anotaba que los habitantes de Santa Cruz nunca habían puesto en duda el derecho de propiedad sobre las tierras antes de la fundación y argumentaban que éste se las tenía arrendadas «de tiempo inmemorial» y le habían «pagado al dueño de la tierra su arrendamiento» ${ }^{83}$.

El conflicto pasó a mayores en mayo de 1756 cuando don Domingo de Camarillo, alcalde pedáneo de la villa de la Soledad, apoyado por Vargas y con la ayuda de los vaqueros del hato de Rompedero, de propiedad de don Andrés de Madariaga, entró al área de Tierra Nueva, lugar cercano a Santa Cruz donde sus habitantes poseían sus ranchos, sementeras y corrales para el ganado y, luego de «notificar la superior orden de voz pública y común» ${ }^{84}$, les incendió sus ranchos, arrasó cañaverales y garrochó sus ganados. Ante la denuncia de los habitantes de Santa Cruz de la acción violenta, la reacción de las autoridades fue de apoyo a los vecinos de Santa Cruz. Primero se envió un agrimensor de la ciudad de Cartagena para que procediera a inventariar los destrozos. Este consignó los estragos en un documento de más de 30 folios y resaltó que Camarillo, acompañado por más de treinta o cuarenta hombres del sitio de Soledad ${ }^{85}$, aparte de arrasar cultivos, se llevó «las vacas paridas que los vecinos de este sitio tienen en la puerta de su casa para la manutención de sus hijos» ${ }^{86}$.

Del inventario de los destrozos causados e inventariados se percibe otro problema, los habitantes de San José de Santa Cruz tenían una producción agrícola que había entrado a competir con la de los productores de la villa de Soledad y los sitios de Santo Tomás, Palmar de Varela y Sabana Grande en los mercados de Santa Marta, San Juan de Ciénaga y la misma Cartagena. Los vecinos de las poblaciones antes mencionadas, ubicadas en el partido de Tierradentro, acusaban a los de San José de Pizarro de abaratar los precios del maíz en el mercado de Santa Marta y les hacían responsables de producir aguardiente de forma clandestina y del robo de ganados en las haciendas del

\footnotetext{
82 Idem.

${ }^{83}$ Levantamiento de Autos por destrucción del sitio de Santa Cruz de Pizarro, Soledad, 11 de enero de 1756, AGN, Santa Fe, leg. 1168.

84 Idem.

${ }^{85}$ Idem.

86 Idem.
} 
área ${ }^{87}$. Al final el sitio tuvo sus tierras comunales y los vecinos de Soledad fueron obligados a pagar los destrozos que causaron por un fiscal de la $\mathrm{Au}-$ diencia de Santa Fe. Aquí, en el escenario del pleito de Santa Cruz de Pizarro, la lectura que ha de hacerse es la de la lucha por terrenos aptos para la ganadería entre vecinos notables y sus redes por el acceso a la mano de obra que se ubicaba a orillas del río Magdalena, entre el canal del Dique y el sitio de Barranquillas. En tanto, los libres escapaban del pago de arrendamiento por sus tierras y se vinculaban a mercados comarcanos, elevando sus ingresos, mientras que la corona garantizaba el flujo de alimentos y hombres necesarios para responder a un supuesto ataque a la ciudad de Cartagena.

Llama la atención que la aplicación de la justicia fue expedita y ejemplarizante, en adelante ningún hacendado podía tomar la justicia en sus manos y proceder a demoler cultivos que considerara estuvieran violando sus derechos de propiedad sin un juicio previo y sin elevar queja a las autoridades competentes. Los libres tenían acceso a la tierra y un cuerpo jurídico y de burócratas que hacia valer ese derecho, por ser estos «leales vasallos del Rey» ${ }^{88}$.

\section{Los libres de Chiriguaná suplican privilegios al Rey: tierras comunales y calidad de villa}

Pero no solo por la vía abierta por Mier se logra la inserción de los libres a la vecindad. Muchos lugares obtuvieron la categoría de sitio de manera casi que inercial. Cerca de las ciudades y villas pobladas desde el siglo XVI, en las zonas de frontera, a orillas del río Magdalena, Cauca, Sinú y San Jorge emergieron numerosos pueblos que ahora eran reconocidos con la categoría de sitio, para ser más exactos, según el censo del año de 1779 existían más 60 pueblos con dicha condición en la gobernación de Cartagena y 25 en la de Santa Marta.

Pero la movilidad propuesta por el reformismo borbónico no quedó allí, ahora, a finales del siglo XVIII y comienzos del XIX, muchos de estos sitios aspiraban a convertirse en villas. Veamos uno de esos casos. Para el año de 1795 sus habitantes se enfrentaron con el comerciante y hacendado momposino Miguel López Bordel en un extenso pleito que duró alrededor de 10 años. Este último había adquirido el hato de San Antonio del Dividivi en el año de 1789, en cuyos bordes se encontraba el sitio de Chiriguaná y, a diferencia

\footnotetext{
${ }^{87}$ Idem. Madariaga era propietario del hato de Rompedero, cercano a Santa Cruz y veía recortadas las posibilidades de usufructuar playones ricos en pastos naturales para sus ganados. 88 Idem.
} 
de los anteriores dueños decidió cobrar arrendamiento a los habitantes del sitio por el uso de tierras que consideraba eran de su propiedad, cuestión que no fue aceptada por la comunidad. Estos últimos remitieron una representación al Rey donde le solicitaban se les adjudicara tierras alrededor del sitio, ya que ellos, a diferencia de otros pueblos, no tenían tierras comunales. Lo cierto es que su petición fue escuchada en la ciudad de Santa Fe de Bogotá y se asignaron funcionarios de la ya, para esa fecha, organizada agencia de manejo de conflictos de tierras instalada por el virrey Guirior y a cargo del funcionario ilustrado Joaquín Ovalle. Este, apoyó las denuncias hechas por el cura del sitio don Salvador Peinado en el sentido de que el sitio debía tener tierras comunales, exactamente tres estancias.

El pleito obligó el traslado de un fiscal de la ciudad de Bogotá a Chiriguaná quien escuchó las partes. Este funcionario por boca de los libres, liderados por el mencionado cura, unos «pardos» y unos «pocos blancos» se enteró del surgimiento del sitio, de que tenían iglesia, pagaban sus diezmos, que eran labradores y habían realizado entradas contra los indios chimilas y motilones. Se supo entonces que los habitantes del sitio tenían la responsabilidad de la defensa de los hatos, cuidado de caminos y transporte de los productos hasta los mercados locales. El abogado del comerciante don López Bordel pretendía mostrar a los dueños del hato como seres desprendidos que daban beneficios a los libres sin obtener ningún favor y emparentaba al sitio a una rochela, guarida de maleantes y prostitutas. El fiscal de lo civil resaltaba como durante 70 años el sitio cumplió con la función de «alejar con ellos a los indios bárbaros y gentiles que infestaban aquella comarca, talaban y destruían los establecimientos de agricultura y cría en lo que ningún otro fue más utilizado que el primero» ${ }^{89}$.

El fallo a favor de los libres llegó en el año de 1803 y reconocía como tierras del común tres estancias alrededor del pueblo, pero, dado el aporte que hacían los habitantes del sitio a la economía y el reconocimiento que eran capaces del «arreglo político», los habitantes de Chiriguaná solicitaron para su población la calidad de villa ${ }^{90}$. Para conseguir dicho ascenso los habitantes del sitio levantaron a su costa un censo que recogía el número de viviendas del sitio, su tamaño, sus habitantes por sexo y nombre, su ocupación y las unidades productivas de estos. De allí sabemos que el sitio tenía dos mil ochocientos siete habitantes, los cuales se dedicaban a la cría de ganados y cultivo de maíz y caña de azúcar, y que eran dueños de 7057 cabezas de ganado vacuno, 3717 caballos y yeguas, 3000 cerdos, 320 cabras y ovejas y 200 labores de plátano,

\footnotetext{
${ }^{89}$ Idem.

90 Sánchez, 2011: 130-155.
} 
cacao, maíz, arroz y 30 trapiches de caña ${ }^{91}$. Este censo, con los argumentos de sus habitantes que sostenían que habían colaborado en las entradas contra indios infieles, abastecían mercados mineros y la ciudad de Mompox, que eran capaces del convenio político, ya que tenían iglesia, pagaban diezmo y contribuían a los estancos reales del tabaco, naipes y aguardientes, llevó a que el sitio de libres de Chiriguaná fuera ascendido a la calidad de villa en el año de 1812 y saliera de la tutela de la ciudad de Tamalameque. En adelante sus habitantes serían capaces del autogobierno, como una ciudad hispana.

Otros sitios vivieron la misma historia en el Nuevo Reino de Granada ${ }^{92}$. La movilidad propiciada por el reformismo borbón no se detenía. Ahora, sitios de libres habitados por descendientes de esclavizados, y que, en sus propias palabras eran «capaces de vivir en República, como dice Aristóteles» solicitaban, como vasallos útiles al Rey otras calidades, ser considerados villanos. El reformismo borbón inauguraba así un espacio de movilidad colectiva gracias a su propuesta de unificación a un nuevo orden estatal que hacía de la integración a la ley y el orden su fortaleza.

\section{CONCLUSIÓN}

Hasta aquí hemos revelado un proceso particular que enlaza elementos de larga duración como el mestizaje con las reformas implementadas por el primer virrey de la Nueva Granada don Sebastián de Eslava a partir del año de 1743 en las gobernaciones de Santa Marta y Cartagena y la emergencia de los sitios habitados por gente libre. Quisimos demostrar que una primera lectura que se hizo de las acciones del virrey Eslava que privilegió el fenómeno coercitivo, no percibió que si bien los reformadores creían en la coerción como elemento fundamental para llevarlas a cabo, también buscaban la integración de sectores de población al estado llano, dotándolos de derechos y deberes y con calidad de vecinos. ${ }^{93}$ Este cambio se enmarca en una tensión mayor, la del tránsito de una forma de gobierno en republicas más o menos autónomas e interdependientes a un tipo de Estado particular que llamaremos Ilustrado que invade lentamente el gobierno de la llamada República Democrática ${ }^{94}$.

${ }^{91}$ Censo del sitio de libres de Chiriguaná, 22 de julio de 1800, AGN, FTM, leg. 132.

92 Garrido, 2007: 245-266.

${ }_{93}$ Guarisco, 2003: 97-121.

${ }^{94}$ En el Diccionario de Autoridades de 1724 se dice que República es: «El gobierno del público. Oy se dice del gobierno de muchos, como distinto del gobierno Monarchico, Porque en cada una de las tres formas de Republica Monarchia, Aristocracia y Democracia, son diversos los gobiernos». Diccionario de Autoridades, 1803: 245. 
Se camina de una libertad fuera del derecho para entrar, ahora, a otra bajo coerción y consenso, con deberes y derechos, con la calidad de vecino y la capacidad de autogobierno, bajo el imperio de la ley y la tutela del Rey.

Por otro lado, la implementación de estas reformas se debía adecuar a otro elemento geopolítico, la defensa y abastecimiento de la ciudad de Cartagena. Para lo primero se debía dar a los libres el status de ciudadano/ miliciano y, para incrementar la producción de alimentos se debían anular los factores que impedían su libre circulación. Los libres, ahora milicianos, debían hacer retroceder a los indios Chimilas que atacaban los hatos y unidades productivas y, por otro, al ser dotados de derechos de propiedad comunal se les eximia del pago de arrendamiento por uso de la tierra de los hacendados locales.

A largo plazo la cuestión se vuelve más compleja y muestra otro aspecto clave de la activación de derechos y deberes ciudadanos a este sector poblacional, su rol dinámico en este escenario. Si por un lado los libres obtienen tierras y defendían ese derecho y aceptaban el status de milicianos -hombres del Rey-, ahora, conscientes de su papel político en el nuevo escenario, exigen una movilidad como cuerpo social, quieren el autogobierno, el cual obtendrían al recibir algunos de estos sitios la calidad de villa. En este sentido la integración de los «libres de todos los colores» al llamado Estado Ilustrado los hacia partícipes de la vida política local. Son estos ciudadanos los que a finales del siglo XVIII reclaman más derechos y una participación activa en las estructuras de gobierno local de sus localidades y chocan con los notables asentados en los cabildos de las ciudades históricas de las mencionadas gobernaciones de Santa Marta y Cartagena. Una historia bastante compleja que se operó gracias al reformismo borbónico.

\section{BiBLIOGRAFÍA}

Borrego, María del Carmen, Palenques de negros en Cartagena de Indias a fines del siglo XVII, Sevilla, Escuela de Estudios Hispano-Americanos, 1973.

Castillo, Norma, "Cohabitación y conflictividad entre afromestizos y nahuas en el México central", Manuel de la Serna (ed.), Pautas de convivencia étnica en la América colonial (Indios, negros, mulatos, pardos y esclavos), México, CCYDELUnam- Gobierno del Estado de Guanajuato, 2005: 163-186.

Cavieres, Eduardo, "Mestizaje y crecimiento de la población iberoamericana en el siglo XVIII", Historia General de América Latina, Procesos americanos hacia la redefinición colonial, vol. 4, Madrid, Ediciones Unesco- Editorial Trotta, 2000: 67-81. 
Colmenares, German, Relaciones e informes de los gobernantes de la Nueva Granada, vol. 1, Bogotá, Banco Popular, 1989.

Conde Calderón, Jorge, Espacio, sociedad y conflictos en la provincia de Cartagena, 1740-1815, Barranquilla, Universidad del Atlántico, 1999.

De Mier, José, Poblamientos en la Provincia de Santa Marta. Siglo XVIII, vol. 1, Bogotá, Colegio Máximo de las Academias de Colombia, 1987.

De Peredo, Diego, "Noticia historial de la provincia de Cartagena de Indias año 1772", Anuario Colombiano de Historia Social y de la Cultura, 6-7 (Bogotá, 1971): 119-154.

De Solórzano, Juan, Política indiana, vol.2, Madrid, Biblioteca de Autores Españoles, 1972.

Fals Borda, Orlando, Historia doble de la Costa. Mompox y Loba, vol.1, Bogotá, Carlos Valencia Editores, 1979.

Gallego, Judith, "Zambaje y conflicto en la Provincia de Cartagena.1602-1640”, Anuario de Historia Regional y de las Fronteras, IX (Bucaramanga, Septiembre de 2004): 49-78.

García, María, Santa Marta durante la guerra de Sucesión española, Sevilla, Escuela de Estudios Hispano-Americanos, 1982.

Garrido, Margarita, "Libres de todos los colores en Nueva Granada: Identidad y obediencia antes de la Independencia”, Cristóbal Aljovín y Nils Jacobsen (eds.), Cultura política en los Andes (1750-1950), Lima, Universidad Nacional de San Marcos, IFEA, 2007: 245-266.

Guarisco, Claudia, "El reformismo borbónico y la participación política de indios y estado llano en el Valle de México", Jahrbuch für Geschichte Lateinamerikas, 40 (Wien, 2003): 97-121.

Guerra, Franklin, Esclavos negros, cimarroneras y cumbes de Barlovento, Caracas, Cuadernos LAGOVEN, 1984.

Gumilla, José, Historia natural, civil y geográfica de las naciones situadas en las riveras del río Orinoco, vol. 1, Barcelona, Imprenta de Carlos Gilbert y Tutó, 1781.

Herrera Ángel, Marta, Ordenar para controlar. Ordenamiento espacial y control político en las Llanuras del caribe y en los Andes Centrales Neogranadinos. Siglo XVII, Bogotá, Icanh-Academia Colombiana de Historia, 2002.

Herrera, "El Arrochelamiento: Nominar para Criminalizar", El Taller de la Historia, I/1 (Cartagena, 2002): 11-46.

Herrera, "Confrontación territorial y reordenamiento espacial, «Chimilas» y «españoles» en la provincia de Santa Marta, Siglo XVIII", Leovedis Martínez y Hugues Sánchez (eds.), Indígenas, poblamiento, política y cultura en el departamento del Cesar, Valledupar, Ediciones Unicesar, 2002: 29-96. 
Herrera Ángel, Marta, “Libres de 'todos los colores': el ordenamiento social en las llanuras del Caribe, siglo XVIII", Alberto Abello (ed.), El Caribe en la nación colombiana, Bogotá, Museo Nacional de Colombia- Observatorio del Caribe Colombiano, 2006: 248-268.

Herzog, Tamar, Vecinos y extranjeros: hacerse español en la Edad Moderna, Madrid, Alianza Editorial, 2006.

Ibarra, Eugenia, "La complementariedad cultural en el surgimiento de los grupos zambos del cabo Gracias a Dios, en La Mosquitia, durante los siglos XVII y XVIII", Revista de Estudios Sociales, 26 (Bogotá, 2007): 105-115.

Kuethe, Allan, "The Status of the Free Pardo in the Disciplined Militia of New Granada", The Journal of Negro History, 56/2 (Riverside, 1971): 105-117.

Kuethe, Allan, Reforma militar y sociedad en la Nueva Granada 1773-1808, Bogotá, Banco de la República, 1993.

Lucena Giraldo, Manuel, "El paraíso estropeado. Imágenes ambiguas de las ciudades americanas a finales del siglo XVIII", Scripta Nova, X/218 (Barcelona, 2006): $1-11$.

Marchena, Juan, "Sin temor de Rey ni de Dios. Violencia, corrupción y crisis de autoridad en la Cartagena colonial", Allan Kuethe y Juan Marchena (eds.), Soldados del Rey, Valencia, Universitat Jaume-I, 2005: 31-100.

Martínez, Gabriel, Cartas de los Obispos de Cartagena de Indias durante el periodo hispánico. 1534-1820, Medellín, Editorial Zuluaga, 1986.

McFarlane, Anthony, Colombia antes de la independencia: economía, sociedad y política bajo el dominio Borbón, Santa Fe de Bogotá, Banco de la República-El Áncora, 1997.

Meisel, Adolfo, "Esclavitud Mestizaje y haciendas en la Provincia de. Cartagena, 1533.1851”, Gustavo Bell (ed.), El Caribe colombiano, selección de textos históricos, Barranquilla, Universidad del Norte, 1998: 69-137.

Mena, María, Santa Marta durante la guerra de Sucesión española, Sevilla, Escuela de Estudios Hispano-Americanos, 1982.

Monod, Paul, "Estado, nación y monarquía en el siglo XVIII: visión comparativa", Conrad Russell y José Andrés-Gallego (eds.), Las Monarquías del Antiguo Régimen, ¿monarquías compuestas?, Madrid, Editorial Complutense, 1996: 11-30.

Monod, Paul, El poder de los reyes: monarquía y religión en Europa 1589-1715, Madrid, Alianza Editorial, 2001.

Mora de Tovar, Gilma, "Poblamiento y sociedad en el bajo Magdalena durante la segunda mitad del siglo XVIII", Anuario Colombiano de Historia Social y de la Cultura, 21 (Bogotá, 1993): 40-62. 
Moreno de Ángel, Pilar, Antonio de la Torre y Miranda, viajero y poblador siglo XVIII, Bogotá, Planeta, 1993.

Navarrete, María; "El palenque de Limón (Cartagena de Indias, siglo XVII): el imaginario del poder y sus jerarquías", Juan de la Serna (ed.), Vicisitudes negro africanas en Iberoamérica, experiencias de investigación, México, Centro de Investigaciones sobre América Latina y el Caribe, UNAM, 2011: 101-134.

Palacios, Joseph, Diario de viaje, entre los indios y negros de la Provincia de Cartagena de Indias en el Nuevo Reino de Granada, 1787-1788, Barranquilla, Ediciones Gobernación del Atlántico, 1994.

Pietschmann, Horst, "Actores locales y poder central: la herencia colonial y el caso de México", Relaciones, XIX/73 (México, 1993): 52-83.

Restrepo, Ernesto, Historia de la provincia de Santa Marta, Bogotá, Imprenta Nacional de Colombia, 1974.

Rojas, Beatriz, “Orden de gobierno y organización del territorio: Nueva España hacia una nueva territorialidad. 1786-1825" Clara García (coord.), Las reformas borbónicas 1750-1808, México, Fondo de Cultura Económica/Centro de Investigación y Docencia Económica, 2010: 130-163.

Rueda, Rocío, Zambaje y autonomía: historia de la gente negra de la provincia de Esmeraldas, Siglos XVI-XVIII, Guayaquil, Municipalidad de Esmeraldas, 2001.

Ruiz, Julián, El cimarronaje en Cartagena de Indias: siglo XVII, Madrid, s.d., 1990.

Sánchez Mejía, Hugues, "Amancebamiento, poligamia, lujuria y otros excesos de la población libre en el Caribe colombiano. El nacimiento de una cultura. 17501880", Hugues Sánchez y Leovedis Duran (comps.), Historia, Identidades, Cultura Popular y Música Tradicional en el Caribe Colombiano, Valledupar, Ediciones Unicesar, 2004: 45-59.

Sánchez Mejía, Hugues, “Esclavitud, zambaje, «rochelas» y otros excesos en la población libre de las gobernaciones de Santa Marta y Cartagena, 1600-1800", Yobenj Chicangana-Bayona (ed.), Historia, cultura y sociedad colonial, siglos XVI-XVIII, Medellín, La Carreta Histórica, 2008: 127-157.

Sánchez Mejía, Hugues, "De esclavos a campesinos, de la «roza» al mercado: tierra y producción agropecuaria de los «libres de todos los colores» en la Gobernación de Santa Marta (1740-1810)", Historia Crítica, 43 (Bogotá, 2011): 130-155.

Suárez, Teresa y Tornay, María, "Poblaciones, vecinos y fronteras rioplatenses. Santa Fe a fines del siglo XVIII", Anuario de Estudios Americanos, 60/2 (Madrid, 2003): 521-555.

Tovar, Hermes; Tovar, Camilo y Tovar, Andrés, Convocatoria al poder del número: censos y estadísticas de la Nueva Granada (1750-1830), Bogotá, Archivo General de la Nación, 1994. 
Waldron, Kathy, "Los pecadores y el obispo en la Venezuela colonial: La visita del obispo Mariano Martí, 1771-1784", Asunción Lavrin (ed.), Sexualidad y matrimonio en la América hispánica, siglos XVI-XVIII, México, Conalcuta- Grijalbo, 1991: 173-196.

Fecha de recepción: 4 de julio de 2013.

Fecha de aceptación: 15 de noviembre de 2013.

\section{From arrochelados to residents: Bourbon reformism and political integration in the governorates of Santa Marta and Cartagena, New Granada, 1740-1810}

In the sixteenth and seventeenth centuries, a particular kind of miscegenation occurred in the governorates of Santa Marta and Cartagena in the New Kingdom of Granada. The arrival of Bourbon reformism in the city of Cartagena in 1740, led by Viceroy Sebastian Eslava, had a major impact on the heterogeneous population who, the authorities considered, lived 'without God or law'. Although, coercion existed in the population policies implemented to control people living in rochelas and/or arrochelados, it was not the main driving force that guaranteed mobilization of groups of people to specific locations called sitios de libres or 'places of free people'. We consider a specific political maneuver by the Viceroy, involving insertion into the neighborhood and the vassalage of the free descendants of slaves and indigenous people, to lie behind this process. We also show how, once the 'free people' were included in the neighborhood and considered the King's vassals, they began to seek greater political mobility.

KeY words: New Kingdom of Granada; Bourbon reformism; zambaje; rochelas; 'free people' of all colors. 